\title{
HIV and other sexually transmitted infection research in the Middle East and North Africa: promising progress?
}

\author{
Laith J Abu-Raddad, ${ }^{1,2,3}$ Khalil G Ghanem, ${ }^{4}$ Ali Feizzadeh, ${ }^{5}$ \\ Hamidreza Setayesh, ${ }^{6}$ Jesus Maria Garcia Calleja, ${ }^{7}$ Gabriele Riedner $^{8}$
}

The mere association of the words sexually transmitted infections (STIs), including HIV/AIDS, and sexuality, to Middle East and North Africa (MENA) in any discussion, social or academic, seems to elicit heated debates and controversy. The MENA region is, in the minds of many, an area where socio-cultural sensitivities surrounding sex and disease still abound. Are there HIV epidemics shrouded behind a wall of denial? Is there a 'conspiracy of silence' resulting in a failure to confront a public health scourge?

Lack of data seems to have fuelled this debate, but the reality of the situation is more nuanced. There are probably shreds of truth in the polemics about HIV infection and other STIs in this region, but partial truths often distort reality. This special supplement of Sexually Transmitted Infections provides a critical piece of the solution to this problem: evidence from the field. This evidence suggests a reality that this region should be able to confront and deal with.

The purpose of this special supplement is to showcase the progress of STI research in MENA, and to demonstrate stronger evidence about the HIV epidemic to inform policy and programming. We chose studies that broadened our knowledge in this field, and testified to the feasibility of conducting quality research in this region. To highlight progress, we

\footnotetext{
${ }^{1}$ Infectious Disease Epidemiology Group, Weill Cornell Medical College-Qatar, Cornell University, Doha, Qatar; ${ }^{2}$ Department of Public Health, Weill Cornell Medical College, Cornell University, New York, New York, USA; ${ }^{3}$ Vaccine and Infectious Disease Division, Fred Hutchinson Cancer Research Center, Seattle, Washington, USA; ${ }^{4}$ Johns Hopkins University School of Medicine, Baltimore, Maryland, USA; ${ }^{5}$ Regional Support Team for Middle East and North Africa, Joint United Nations Programme on HIV/AIDS (UNAIDS), Cairo, Egypt; ${ }^{6}$ Sudan Country Office, Joint United Nations Programme on HIVIAIDS (UNAIDS), Khartoum, Sudan; 'HIV Department, World Health Organization, Geneva, Switzerland; ${ }^{8}$ Regional Office of the Eastern Mediterranean, World Health Organization, Cairo, Egypt

Correspondence to Dr Laith J Abu-Raddad, Infectious Disease Epidemiology Group, Weill Cornell Medical College-Qatar, Qatar Foundation-Education City, P.O. Box 24144, Doha, Qatar; lja2002@qatar-med.cornell.edu
}

invited contributors to submit studies dealing with diverse research questions and methodologies. We encouraged novelty and weighed the studies' potential to impact policy and programming. Our goal was to have a broad representation from the MENA region, but we only achieved partial success. Though eventually the supplement included data from multiple countries in one form or another, the countries with more advanced research capacity contributed more. A few of the invited articles from other countries did not materialise for a variety of reasons. One of the greatest challenges facing research in the MENA region is the paucity of trained investigators. Although this supplement provides evidence that a core group of investigators are actively conducting vital research in the region, the challenge of further expanding the field remains.

MENA, in this supplement, extends from Morocco in the West to Afghanistan and Pakistan in the East (figure 1). It is a diverse region that comprises more than $10 \%$ of the World's 15-49 age group population. Recently, the region has attracted global attention with its youth movements, known as the Arab Spring, that swept through the region and roiled decades-old regimes. Regrettably the region has largely failed to benefit from its demographic dividend. There are, however, bright spots. This supplement highlights the outcome of research conducted mostly by young and motivated local investigators, working in challenging conditions.

This supplement is the result of concerted efforts by many individuals and organisations over 2 years. These efforts were spearheaded and funded by the Eastern Mediterranean Regional Office of the WHO (WHO/EMRO), the Regional Support Team for MENA of the Joint United Nations Programme on HIV/AIDS (UNAIDS MENA), and the Weill Cornell Medical College-Qatar. This endeavour was envisioned to address a structural weakness of HIV efforts in the MENA region. Many of the studies were conducted or supported through national programmes that had limited interest in using the data beyond informing HIV policy, and possibly some programming at the national level. ${ }^{12}$ To alleviate this challenge, the MENA Regional Expert Group on HIV Surveillance and Strategic Information recommended, ${ }^{3}$ in its meeting in May of 2011 in Cairo, Egypt, the establishment of an editorial support team from the members of this group, to assist authors from the region in drafting the results of their investigations (please note the Acknowledgment below). The supplement is the outcome of this effort.

The first article in this supplement describes the progress in HIV research in the MENA region since the discovery of the epidemic. ${ }^{4}$ Saba et al show that published reports on HIV in the MENA region have been steadily increasing over the years with much of the progress occurring in the last few years. Reports on $\mathrm{HIV}$ in the MENA region now account for about $1 \%$ of the global reports on HIV, a fact that may surprise some. Though there are still large gaps, the progress has been solid in both quantity and quality of product. This optimistic finding, however, is tempered by several important pitfalls which include significant heterogeneity in the progress among countries, a large volume of scientific work conducted but not published in the scientific literature, and the critical need to ensure quality standards in research methodology regardless of whether it is conducted by academia or not. The article is followed by an editorial by Nasirian et $a l^{5}$ which points to some of the barriers facing researchers when publishing their results.

Bozicevic et $a l^{6}$ then provide an encompassing overview of the development, quality and progress of HIV surveillance in the 23 MENA countries through a large effort led by WHO/EMRO to assess the capacity of HIV surveillance systems in this region. The study highlights recent progress, but again emphasises its heterogeneity across countries. Though four countries have fully functioning systems, close to half of MENA countries lag far behind, to the extent that we have limited knowledge of the epidemic in these countries. These data suggest that much work still needs to be done before we have functioning and durable HIV surveillance systems that monitor epidemic trends and generate data that can inform HIV policy and programming.

These papers are followed by several HIV surveillance studies of different populations in different countries. In the first of these, Elhadi et $a l^{7}$ present the 


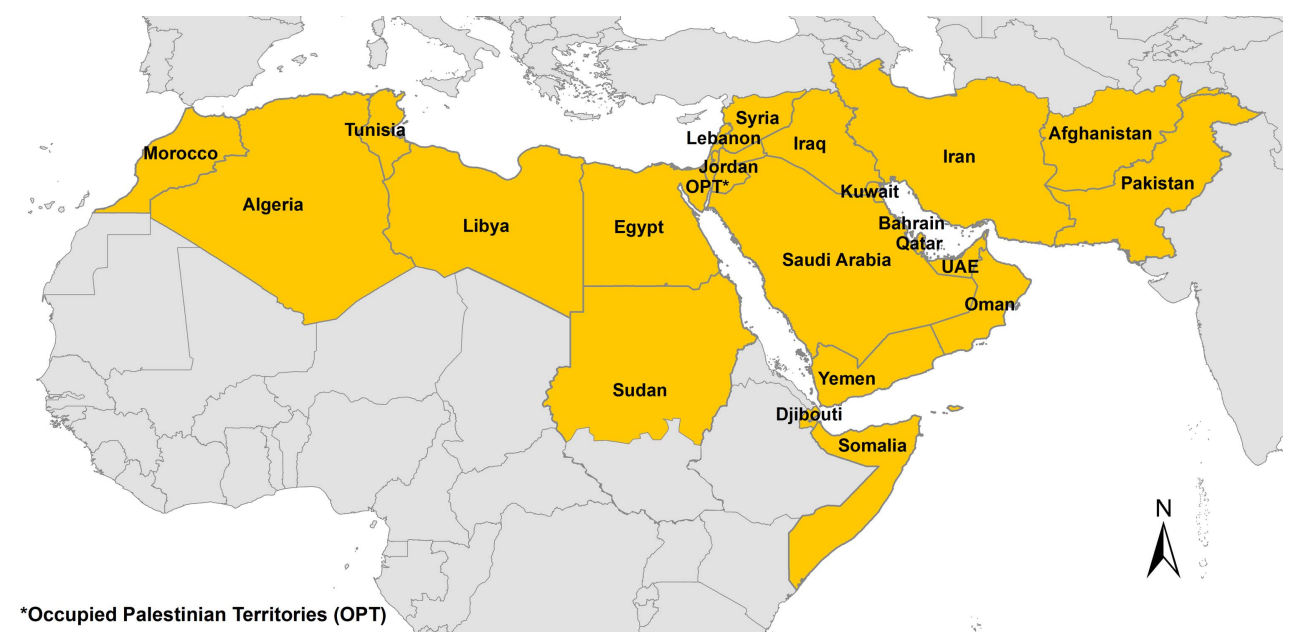

Figure 1 Map of the Middle-East and North Africa region as defined in in this supplement. The definition, per United Nations agencies, includes 23 countries or territories: Afghanistan, Algeria, Bahrain, Djibouti, Egypt, Iran, Iraq, Jordan, Kuwait, Lebanon, Libya, Morocco, Occupied Palestinian Territories, Oman, Pakistan, Qatar, Saudi Arabia, Somalia, Sudan, Syria, Tunisia, United Arab Emirates, and Yemen. Access the article online to view this figure in colour.

results of a remarkable large-scale surveillance project that we hope can inform the approach that should be taken in other MENA countries. The authors measured HIV, syphilis and hepatitis C prevalence among female sex workers (FSWs) in 14 of the 15 states of Sudan using state of the art sampling methods. The study showed how the HIV epidemic was a reality in commercial heterosexual sex networks in Sudan, but that HIV prevalence varied widely from one state to another. This kind of evidence provides strategic data for HIV policy and programming, and emphasises the need to prioritise HIV response and resource allocation based on local epidemiology. The study also highlighted how HIV prevention needs were not being met in this population.

Emmanuel et $a l^{8}$ then provide the results of Pakistan's fourth round of second generation surveillance among at-risk key populations including people who inject drugs (PWID), transgender people, and male and female sex workers. The study highlights how one MENA country has succeeded in establishing an advanced surveillance research. These rounds of mapping and surveillance in Pakistan have managed to establish a detailed description of the epidemic and its evolution throughout the country, a feat that has only been achieved by a handful of countries worldwide. The results of the study provide a stern and sobering warning to other MENA countries: the HIV epidemic is a growing reality that must be countered by an aggressive response. If HIV infection transmission is not controlled in one at-risk population, it can spread.
Along the same lines, a group of brief articles from Iran report the findings of HIV surveillance in four different population groups. In the first of these, Khajehkazemi et al present the results of the national bio-behavioral survey among PWID. ${ }^{9}$ The findings affirm that this population group remains the most affected by the HIV epidemic in this country, and still exhibit high levels of risktaking behaviours despite a roll-out of harm reduction interventions. ${ }^{10}{ }^{11}$ In the second article, Navadeh et $a l^{12}$ present the results of the national bio-behavioral survey among prisoners. Their findings are indicative of the overlapping networks of HIV transmission among PWID and prisoners, which appear to be a concern not only in Iran, but also in other MENA countries. ${ }^{1}$ It is clear that prisons should be considered as a priority setting for HIV prevention in at least a few MENA countries. Sajadi et al present the results of the first national bio-behavioral survey among FSWs in Iran, a long-awaited study after years in which most surveillance work was focused on PWID. ${ }^{13}$ The study demonstrates the direct links between FSWs and PWID in Iran through which HIV infection can be bridged. Though the study is not conclusive, it suggests the potential for considerable HIV sexual transmission in commercial sex networks, a lesson highlighted in the neighbouring country of Pakistan. ${ }^{8}$

In the last article from Iran, Alipour et al present the results of a novel study for this region: A national bio-behavioral survey among partners of PWID. ${ }^{14}$ The study demonstrates that despite the difficulty in reaching this population, it is an important group to consider when trying to define the complexity of the HIV epidemic in Iran. Though the main factors of HIV transmission in this region are the networks of high-risk populations, a substantial burden of the infection is being borne by spouses who may not fit the typical high-risk description. ${ }^{1}{ }^{2}$ The study challenges us to develop appropriate interventions for this vulnerable population, and provides evidence of the importance and feasibility of recruiting spouses of people who engage in high-risk behaviour.

Morocco then contributes two studies to our supplement. In the first one, Johnston et $a l^{15}$ report the findings of HIV and syphilis surveillance among men who have sex with men (MSM), the most stigmatised of the key at-risk populations in this region. The paper shows the feasibility of conducting scientifically rigorous studies among MSM in at least some parts of MENA, and the importance of working with them given the evidence of emerging HIV epidemics in this population in this region. ${ }^{16}$

In the second article from Morocco, Mumtaz et $a l^{17}$ present the first attempt to map HIV transmission and its sources in a MENA country, by conducting an HIV Mode of Transmission Analysis (MoT) modelling study. The findings show how HIV transmission in this country is driven by the sexual and injecting networks of the key populations at risk, and that these vulnerable populations should be the priority of HIV prevention programmes. Importantly, the study demonstrates how Morocco has leveraged the knowledge of the epidemiology of its HIV infections, ${ }^{18}{ }^{19}$ to generate an evidence-informed and priority-tailored 
HIV response. The success of this study in influencing national policy and programming also points to the role that academia can play in supporting national programmes to develop an effective HIV response.

Despite the progress of HIV research in MENA, the progress in understanding the disease burden of other STIs is woefully lagging. The supplement concludes with the first study of Chlamydia trachomatis in Qatar, a welcome addition considering the limited research on HIV and other STIs that has been conducted in this part of MENA. ${ }^{20}$ Al-Thani et al present the results of a survey of $C$ trachomatis among women, and their findings suggest that the disease burden of STIs, even in a sexually conservative society, could be significant within a context of limited STI management. This study is a sobering reminder of the potential for significant reproductive sequelae with no prevention and treatment programming targeting STIs.

These articles testify to the progress of HIV and other STI research in MENA, but they also show that the most solid progress is mainly limited to HIV surveillance. Some areas of research are nearly non-existent, such as implementation science and operations research. Public health authorities in MENA have increasingly acknowledged that, in order to understand the dynamics of the HIV epidemic in their countries, it is important to know the trends in HIV and risk behaviour among the key populations at risk. Nevertheless, the readiness to invest domestic resources in bio-behavioral HIV surveillance surveys remains very limited. The growing amount of data on HIV and risk behaviours, as this supplement clearly shows, has largely been facilitated by external financial and technical support from international donors and United Nations agencies. A major international donor agency, the Global Fund to Fight AIDS, Tuberculosis and Malaria (GFATM) has contributed to funding bio-behavioral surveys in Afghanistan, Egypt, Iran, Jordan, Morocco, Pakistan, Somalia, Sudan, Tunisia, and Yemen. Much of the quality surveillance studies have been conducted thanks to GFATM funding. There is a concern that the GFATM may increase its focus on high HIV burden countries while reducing its support to countries with comparatively lower burden, as in the MENA region, and that governments may not ensure continuity. Accordingly, the sustainability of this progress is at risk if national governments do not invest resources in HIV and other STI research and programming.
The current financial climate may result in stagnating or even diminishing international support for STI research and programme delivery. International development aid should be viewed as a transitional phase focused on capacity building to conduct this type of research and start new surveillance, treatment, and prevention programmes. A guiding experience to this end is the Avahan initiative in India, a large-scale HIV intervention programme focused on the key populations at risk in the six most affected states, and that have demonstrated an impact on the epidemic. ${ }^{21-23}$ For nearly a decade, the Bill and Melinda Gates Foundation invested close to half a billion dollars to build capacity for HIV and STI programmes through HIV services such as HIV testing, care, and treatment, STI testing and treatment, condom promotion, behaviour change communication, stigma reduction, peer education, community mobilisation, and advocacy. ${ }^{21} 2324$ A key aspect of the programme had been the emphasis on scientific research to generate data that can inform HIV policy and programming, and to monitor and evaluate progress and output. ${ }^{22} 24$ This massive programme was then gradually transitioned to the government of India and other partners, ensuring sustainability for the years to come, beyond development aid and donor funding. ${ }^{25}$ Such successful model offers a sustainability strategy with ensured country ownership of the programmes.

In conclusion, this supplement is a testament to the progress in HIV research in MENA over the last few years. Conducting research on STIs is feasible in this region despite the challenges. Although the trend of progress is encouraging, the scale is still inadequate. The region's STI research output is far below what is needed, and diverse areas of STI research are still primitive. This progress should be seen as a promising beginning, but one that needs to be actively nurtured to ensure the desired end. Governments in MENA countries must actively invest financial resources, and promote the development of a research infrastructure, that can capitalise on this progress.

Acknowledgements This special issue was made possible thanks to the contributions of the members of the Sexually Transmitted Infections Supplement Advisory Board: Ivana Bozicevic, Ali-Akbar Haghdoost, Lisa G. Johnston, and Willi McFarland. These individuals have committed time and effort to support authors in drafting their manuscripts, reviewed and edited manuscripts, and facilitated the logistics of this supplement. This special issue is a product of a concerted effort by the Eastern Mediterranean Regional Office of the World Health Organization, the MENA Regional Support Team of UNAIDS, the Joint United Nations Programme on HIV/AIDS, the Regional Expert
Group on HIV Surveillance and Strategic Information for the Middle East and North Africa, and the Infectious Disease Epidemiology Group at Weill Cornell Medical College-Qatar.

Funding Funding for the production of this special issue was provided by the Eastern Mediterranean Regional Office of the World Health Organization and the MENA Regional Support Team of UNAIDS, the Joint United Nations Programme on HIVIAIDS. Additional funding was provided by Qatar National Research Fund (NPRP 4-924-3-251).

Competing interests None.

Patient consent Obtained.

Provenance and peer review Commissioned; internally peer reviewed.

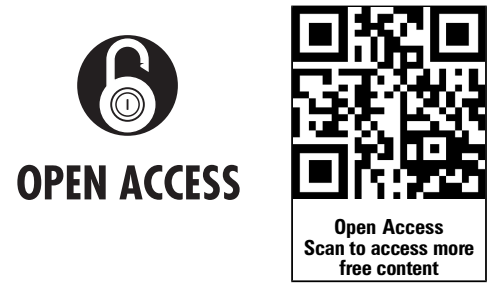

Open Access This is an Open Access article distributed in accordance with the Creative Commons Attribution Non Commercial (CC BY-NC 3.0) license, which permits others to distribute, remix, adapt, build upon this work non-commercially, and license their derivative works on different terms, provided the original work is properly cited and the use is noncommercial. See: http://creativecommons.org/licenses/ by-nc/3.0/

To cite Abu-Raddad LJ, Ghanem KG, Feizzadeh A, et al. Sex Transm Infect 2013;89:iii1-iii4.

Received 19 September 2013

Accepted 30 September 2013

Sex Transm Infect 2013;89:iii1-iii4. doi:10.1136/sextrans-2013-051373

\section{REFERENCES}

1 Abu-Raddad L, Akala FA, Semini l, et al. Characterizing the HIVIAIDS epidemic in the Middle East and North Africa: time for strategic action. Middle East and North Africa HIVIAIDS epidemiology synthesis project. World bank/UNAIDS/WHO publication. Washington, DC: The World Bank Press, 2010

2 Abu-Raddad LJ, Hilmi N, Mumtaz G, et al. Epidemiology of HIV infection in the Middle East and North Africa. AIDS 2010;24(Suppl 2):S5-23.

3 Regional Office of the Eastern Mediterranean, World Health Organization. Meeting of Regional Experts on Surveillance and Strategic Information for the Middle East and North Africa, May 3-5, 2011, Cairo, Egypt. Summary report. Cairo, Egypt: Regional Office of the Eastern Mediterranean, World Health Organization, 2011

4 Saba HF, Kouyoumjian SP, Mumtaz GR, et al. Characterising the progress in HIVIAIDS research in the Middle East and North Africa. Sex Transm Infect 2013;89:iii5-9.

5 Nasirian M, Karamouzian M, Haghdoost AA. Why is the number of HIVIAIDS-related publications low in the MENA region? Sex Transm Infect 2013; 89:iii 10.

6 Bozicevic I, Riedner G, Calleja JM. HIV surveillance in MENA: recent developments and results. Sex Transm Infect 2013;89:iii11-16. 
7 Elhadi M, Elbadawi A, Abdelrahman S, et al. Integrated bio-behavioural HIV surveillance surveys among female sex workers in Sudan, 2011-2012. Sex Transm Infect 2013;89:iii17-22.

8 Emmanuel $F$, Salim M, Akhtar $N$, et al. Second-generation surveillance for HIVIAIDS in Pakistan: results from the 4th round of Integrated Behavior and Biological Survey 2011-2012. Sex Transm Infect 2013;89:iii23-28.

9 Khajehkazemi R, Osooli M, Sajadi L, et al. HIV prevalence and risk behaviours among people who inject drugs in Iran: the 2010 National Surveillance Survey. Sex Transm Infect 2013;89:iii29-32.

10 Razzaghi E, Nassirimanesh B, Afshar $\mathrm{P}$, et al. HIVIAIDS harm reduction in Iran. Lancet 2006;368:434-5.

11 Abu-Raddad L, Akala FA, Semini I, et al. Policy Notes. Characterizing the HIVIAIDS epidemic in the Middle East and North Africa: Time for Strategic Action. Middle East and North Africa HIVIAIDS Epidemiology Synthesis Project.World Bank/UNAIDS/ WHO Publication. Washington, DC: The World Bank Press, 2010.

12 Navadeh S, Mirzazadeh A, Gouya MM, et al. HIV prevalence and related risk behaviours among prisoners in Iran: results of the national biobehavioural survey, 2009. Sex Transm Infect 2013;89:iii33-36.

13 Sajadi L, Mirzazadeh A, Navadeh S, et al. HIV prevalence and related risk behaviours among female sex workers in Iran: results of the national biobehavioural survey, 2010. Sex Transm Infect 2013;89:iii37-40.

14 Alipour A, Haghdoost AA, AA L, et al. HIV prevalence and related risk behaviours among female partners of male injecting drugs users in Iran: results of a bio-behavioural survey, 2010. Sex Transm Infect 2013;89:iii41-44.

15 Johnston LG, Alami K, El Rhilani MH, et al. HIV, syphilis and sexual risk behaviours among men who have sex with men in Agadir and Marrakesh, Morocco. Sex Transm Infect 2013;89:iii45-8

16 Mumtaz G, Hilmi N, McFarland W, et al. Are HIV epidemics among men who have sex with men emerging in the Middle East and North Africa?: a systematic review and data synthesis. PLoS Med 2010;8:e1000444.

17 Mumtaz GR, Kouyoumjian SP, Hilmi N, et al. The distribution of new HIV infections by mode of exposure in Morocco. Sex Transm Infect 2013;89: iii49-56.

18 Kouyoumjian SP, Mumtaz GR, Hilmi N, et al. The epidemiology of HIV infection in Morocco: systematic review and data synthesis. Int I STD AIDS 2013;24:507-16.

19 Mumtaz G, Hilmi N, Zidouh A, et al. HIV modes of transmission analysis in Morocco. Kingdom of Morocco Ministry of Health and National STI/AIDS Programme, Joint United Nations Programme on HIV/ AIDS, and Weill Cornell Medical College-Qatar. 2010
20 Al-Thani $\mathrm{A}$, Abdul-Rahim $\mathrm{H}$, Alabsi $\mathrm{E}$, et al. Prevalence of Chlamydia trachomatis infection in the general population of women in Qatar. Sex Transm Infect 2013;89:iii57-60.

21 Bill \& Melinda Gates Foundation. Avahan-the India AIDS initiative. Fact sheet. http://docs. gatesfoundation.org/avahan/documents/avahan factsheet.pdf (accessed2 Sep 2013)

22 Saidel T, Adhikary R, Mainkar M, et al. Baseline integrated behavioural and biological assessment among most at-risk populations in six high-prevalence states of India: design and implementation challenges. AIDS [Research Support, Non-U.S. Gov't]. 2008;22(Suppl 5): S17-34.

$23 \mathrm{Ng} \mathrm{M}$, Gakidou E, Levin-Rector A, et al. Assessment of population-level effect of Avahan, an HIV-prevention initiative in India. Lancet [Research Support, Non-U.S. Gov't]. 2011;378: 1643-52.

24 Sgaier SK, Claeson M, Gilks C, et al. Knowing your HIVIAIDS epidemic and tailoring an effective response: how did India do it? Sex Transm Infect 2012;88:240-9.

25 Sgaier SK, Ramakrishnan A, Dhingra N, et al. How the Avahan HIV prevention program transitioned from the Gates Foundation to the government of India. Health Aff (Millwood) [Research Support, Non-U.S. Gov't]. 2013;32: 1265-73. 